\title{
Impact of wind speed and air pollution on COVID-19 transmission in Pakistan
}

\author{
Q. Ali ${ }^{1}$ A. $\operatorname{Raza}^{2} \cdot$ S. Saghir ${ }^{3}$ M.T. I. Khan ${ }^{4}$ (I)
}

Received: 30 July 2020 / Revised: 18 December 2020 / Accepted: 15 February 2021 / Published online: 13 March 2021

(C) Islamic Azad University (IAU) 2021

\begin{abstract}
This study investigated the effect of wind speed and air pollution on COVID-19 from March 10, 2020, to October 04, 2020, in Pakistan. Wind speed and COVID-19 had positive correlation in Pakistan and its provinces. The inverted U-shaped doseresponse curve was found for wind speed and COVID-19 in Punjab. Initially, the dose-response curve showed a positive link between wind speed and COVID-19 in Pakistan, Sindh, Khyber Pakhtunkhwa, and Islamabad Capital Territory. Later, it becomes downward sloped in Sindh, Khyber Pakhtunkhwa, and Islamabad Capital Territory. The expected log count of COVID-19 was increased by 0.113 times (Pakistan), 0.074 times (Punjab), 0.042 times (Sindh), and 0.082 times (Khyber Pakhtunkhwa) for a $1 \mathrm{~km} / \mathrm{h}$ increase in the wind speed. The correlation between particulate matter and COVID-19 was positive (Pakistan, Punjab, and Islamabad Capital Territory) and negative (Sindh). The dose-response curve for particulate matter and COVID-19 had inverted U-shaped (Pakistan, Punjab, and Khyber Pakhtunkhwa) positively sloped (Islamabad Capital Territory), and negatively sloped (Sindh). The inverted U-shaped association shows that the COVID-19 initially increased due to a rise in the particulate matter but reduced when the particulate matter was above the threshold level. The particulate matter was also responsible to wear face masks and restricted mobility. The expected log count of COVID-19 cases was reduced by 0.005 times in Sindh for 1 unit increase in particulate matter. It is recommended to reduce particulate matter to control respiratory problems. The government should use media (print, electronic, social) and educational syllabus to create awareness about precautionary measures.
\end{abstract}

Keywords Coronavirus · Count data model · Dose-response curve · Generalized Poisson regression · Particulate matter · Public health

\section{Introduction}

The severe acute respiratory syndrome coronavirus (SARSCoV-2), called COVID-19, is an infectious disease, which was initially reported in Wuhan, China in December 2019

Editorial responsibility: Samareh Mirkia.

M. T. I. Khan

tariqiqbal88@yahoo.com

1 Department of Economics, Virtual University of Pakistan, Faisalabad, Pakistan

2 Department of Molecular Biology, Virtual University of Pakistan, Faisalabad, Pakistan

3 Department of Economics, Virtual University of Pakistan, Lahore, Pakistan

4 Department of Economics, Government Postgraduate College, Jaranwala 37200, Pakistan
(Rendana 2020). The signs of COVID-19 were high fever, sore throat, fatigue, shortness of breath, dry cough, and pneumonia (Rendana 2020). The COVID-19 was also accountable for kidney failure, pneumonia, acute respiratory syndrome, and death in severe cases (Raza et al. 2020).

The World Health Organization (WHO) declared a public health emergency due to the COVID-19 outbreak. The continuous rise in the COVID-19 was reported all over the world (Rendana 2020). The COVID-19 was accountable for $39,196,259$ cases and 1,101,298 deaths in more than 200 countries (WHO 2020). Due to the COVID-19, the governments tried to stop the spread through different measures like social distancing, lockdowns, ban on public events or gatherings, closure of academic institutions, closures of transport, and closure of non-essential business (Siciliano et al. 2020). Considering the extra-human factors, environmental factors could influence the COVID-19 transmission, which makes it 
necessary to investigate the drivers of the COVID-19 transmission (Rosario et al 2020).

The literature stated that the COVID-19 was spread from one to another person through respiratory droplets and physical contact (Huang et al. 2020; Shereen et al. 2020). The COVID-19 virus was found in aerosols up to $3 \mathrm{~h}$ (postaerosolization), $4 \mathrm{~h}$ (copper), $24 \mathrm{~h}$ to $37 \mathrm{~h}$ (cardboard), and 2-3 days (stainless and plastic steel) (Rendana 2020). Due to this, Chan et al. (2020) reported that environmental factor like wind speed was a reliable indicator to investigate the viability, spread, and transmission of COVID-19. The variations in climatic indicators were associated with the transmission of infectious diseases (Stott 2016). Many infectious diseases were influenced by environmental indicators such as the SARS outbreak had linked with environmental indicators (Raza et al. 2020). Xu et al. (2020) also revealed the association of meteorological indicators and air quality with the transmission of SARS and MERS.

The polluted air was responsible for about 4.3 million deaths in the world. The concentration of particulate matter (PM) was associated with the increase in cardiovascular diseases, diabetes, asthma, and cancers. Air pollution was linked with influenza, pneumonia and acute lower respiratory infections, and SARS. The PM is a basic component of air pollution and can remain in the air for hours. The airborne PM2.5 has been linked with the transmission of influenza and respiratory infection (Xu et al. 2020).

In Pakistan, the COVID-19 was initially reported on 26th February 2020 (Syed and Sibgatullah 2020). In Pakistan, the COVID-19 was accountable for 323,019 cases and 6654 deaths, as of October 18, 2020 (Government of Pakistan 2020). According to the WHO, the government of Pakistan should take necessary precautionary steps to stop COVID-19 (Khan et al. 2020). The government of Pakistan directed the general public to stay in homes, wear a mask, hand washing, avoid face touching, avoid public places, and maintain social distance to stop the COVID-19 transmission (Raza et al. 2020). The statistics of COVID-19 are still serious in Pakistan (Fig. 1).

Cai et al. (2007) investigated the effect of meteorological variables (wind speed, sunshine, temperature, and humidity) and air pollution on the SARS virus. The atmospheric pollution, like particulate matter (PM), was responsible for serious diseases in human beings (Toppi et al. 2020). Andree (2020) reported that PM2.5 is a factor behind COVID-19 transmission in the Netherlands. The expected increase in the COVID-19 was $100 \%$ for $20 \%$ increase in the concentrations of pollution. In Pakistan, air pollution is accountable for $22 \%$ of premature deaths. Different cities in Pakistan were included in the list of polluted cities in the world (IQAir 2019). Bashir et al. (2020) examined the association of climate indicators (wind speed, humidity, temperature, rainfall, and air quality) with COVID-19 in United
States. Correlation analysis confirmed the linkages between COVID-19 and climate indicators.

The present study aims to examine the impact of wind speed and air pollution (PM2.5) on COID-19 cases in Pakistan, its provinces, and the Islamabad Capital Territory. The contribution of this study in the literature is (a) it first time examines the association of wind speed and PM2.5 with the COVID-19 in Pakistan, (b) it first time examines the association of wind speed and PM2.5 with the COVID-19 in Punjab, Sind, Khyber Pakhtunkhwa (KPK), and Islamabad Capital Territory (ICT), and (c) it used generalized Additive Model to construct dose-response curve between environmental variables (wind speed and PM2.5) and COVID-19 cases, (d) it used generalized Poisson regression technique to empirically find the effect of wind speed and PM2.5 on COVID-19 cases.

Pakistan was ranked in the 23rd position according to the total COVID-19 cases. Pakistan ranked at 6th and 36th position with respect to the population and land area, respectively. Pakistan has 2.08 billion population, showing $2.4 \%$ annual population growth rate. The economy of Pakistan was primarily based on the agriculture sector and has 1629 USD per capita annual income (Hussain et al. 2018). Pakistan is located between latitudes $24^{\circ} \mathrm{N}-37^{\circ} \mathrm{N}$ and longitudes $60^{\circ} \mathrm{E}-75^{\circ} \mathrm{E}$. The climate of Pakistan is generally arid to semiarid, having both monsoon and western system rainfall (Raza et al. 2020).

This study used data on daily COVID-19 statistics from March 10, 2020, to October 04, 2020, in the case of Pakistan, its provinces (Punjab, Sindh, KPK), and ICT. The COVID-19 related data were obtained from the Government of Pakistan (Government of Pakistan 2020), and environmental data like wind speed $(\mathrm{km} / \mathrm{h})$ and particulate matter (PM2.5) were obtained from the Air Quality Open Data Platform (Air Quality Open Data Platform 2020). This research investigated the link between environmental variables and the infection rate of COVID-19, which was estimated as (Raza et al. 2020):

Infection Rate $=\frac{\text { Number of COVID }-19 \text { cases }}{\text { Days of COVID }-19 \text { Infection (Outbreak) }}$.

Different software (R software, STATA 15, and Eviews 10) were used for the empirical analysis.

\section{Materials and methods}

\section{Correlation analysis}

The degree of correlation among environmental variables and COVID-19 was investigated using both Spearman's and Kendall's rank correlation tests. These tests were 


\begin{tabular}{|c|c|c|c|c|}
\hline $\begin{array}{l}\text { Confirmed Cases } \\
323,452\end{array}$ & $\begin{array}{l}\text { Active cases } \\
9,384\end{array}$ & $\begin{array}{l}\text { Deaths } \\
6,659\end{array}$ & $\underbrace{5}_{2.1 \%}$ & 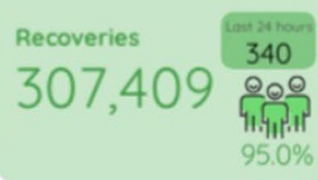 \\
\hline & $\begin{array}{l}\text { Confirmed } \\
\text { Cases }\end{array}$ & $\begin{array}{l}\text { Active } \\
\text { Cases }\end{array}$ & Deaths & Recoveries \\
\hline AJK & 3,498 & 822 & 82 & 2,594 \\
\hline Balochistan & 15,688 & 210 & 148 & 15,330 \\
\hline GB & 4,059 & 255 & 90 & 3,714 \\
\hline Islamabad & 18,069 & 1,130 & 195 & 16,744 \\
\hline KPK & 38,645 & 416 & 1,265 & 36,964 \\
\hline Punjab & 101,652 & 2,116 & 2,298 & 97,238 \\
\hline Sindh & 141,841 & 4,435 & 2,581 & 134,825 \\
\hline
\end{tabular}

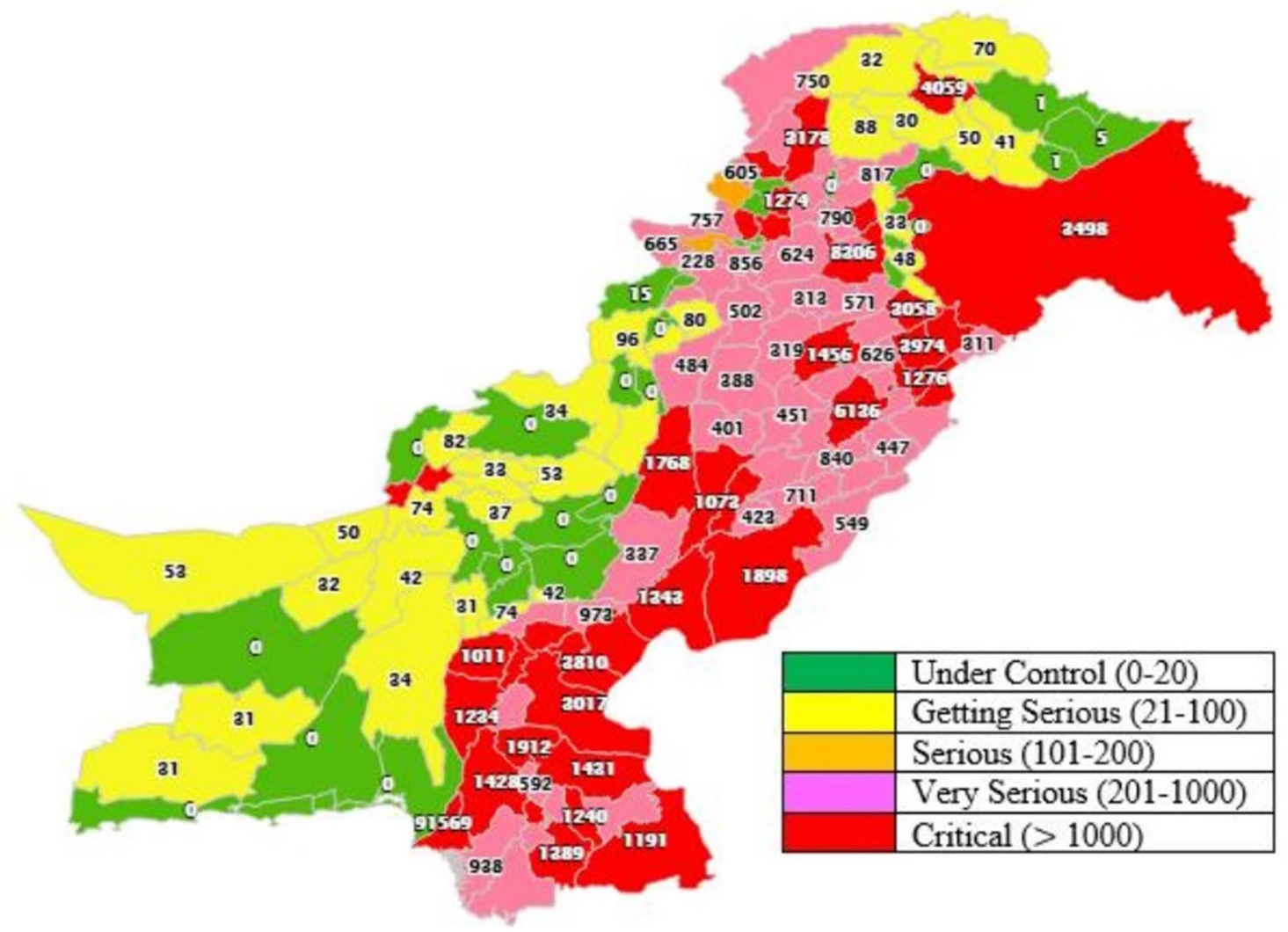

Fig. 1 National and provincial COVID-19 statistics (as of October 19, 2020)

nonparametric tests, computed on ranks (Hamadeh et al. 2017; Raza et al. 2020). Spearman's rank correlation analysis used a monotonic function to find the correlation between two variables. The mathematical expression of Spearman's rank correlation coefficient (Raza et al. 2020) is expressed as: 
$r_{s}=1-6 \frac{\sum d_{i}^{2}}{n\left(n^{2}-1\right)}$

where $n$ is the number of alternatives, and $d_{i}$ shows the difference between the ranks of two parameters (Raza et al. 2020). This study also used Kendall's rank correlation coefficient $(\tau)$ (Kocsis and Anda 2018), which was expressed as (Raza et al. 2020):

$\tau=\frac{S}{D}$

where $S$ is the trend and $D$ is the possible data pairs by using $n$ datasets (Raza et al. 2020):

$D=\left(\begin{array}{l}n \\ 2\end{array}\right)$.

\section{Dose-response curve}

A generalized linear model was used to find the association of various environmental indicators with the COVID19. The generalized additive model (GAM) shows a relation between the predictor variables $(\mathrm{Xi})$ and the univariate response variable $(Y)$ (Raza et al. 2020). However, the exponential family of distribution for $Y$ was normal, binomial, and Poisson (Goswami et al. 2020). The GAM was used to fit equations and splines to investigate the dose-response impact between environmental indicators and the COVID19. The GAM was applied to explore the link for environmental indicators and health outcomes (Raza et al. 2020). This study used an additive and semi-parametric (Raza et al. 2020) polynomial model, as:

$\log y_{t}=\beta_{0}+\beta_{1} x_{t}^{3}-\beta_{2} x_{t}^{2}+\beta_{3} x_{t}+s\left(\mathrm{WS}_{t}\right)+s\left(\mathrm{PM}_{t}\right)+\varepsilon_{t}$

where $y$ represents the COVID-19 infection on day $t, \beta_{0}$ is the intercept, $s(\bullet)$ is a spline function, having two degrees of freedom to avoid over-fitting, $\beta$ is the parameter of $x$, and $x$ denotes the outbreak days, WS shows the wind speed $(\mathrm{km} / \mathrm{h})$, and PM shows the concentration of Particulate Matter in the atmosphere. The expression $s(\bullet)$ was used to control the confounding of explanatory variables because a smooth spline function can control the impact of confounding factors (Raza et al. 2020). However, Raza et al. (2020) reported the advantage of the linear function between environmental indicators and COVID-19, expressed as:

$\log y_{t}=\beta_{0}+\beta_{1} x_{t}^{3}-\beta_{2} x_{t}^{2}+\beta_{3} x_{t}+\beta_{4} \mathrm{WS}_{t}+\beta_{5} \mathrm{PM}_{t}+\varepsilon_{t}$.

A dose-response curve linked multiple dose-variables $(x)$ with the probability of response-variable (infection) (Brouwer et al. 2017; Raza et al. 2020). In other words, the dose-response curve revealed the expectation of potential loss due to various environmental variables (Raza et al. 2020; Ye et al. 2020). This study applied the GAM to draw a dose-response curve between dose variables (outbreak days, wind speed, and PM2.5) and response variables (COVID-19 infection).

\section{Regression analysis}

The generalized Poisson regression is the generalization of standard Poisson regression (Maxwell et al. 2018; Raza et al. 2020), used to find the link between environmental indicators and COVID-19. The generalized Poisson regression used positive as well as negative correlations between the variables (Consul and Famoye 1992; Famoye 2015; Raza et al. 2020). The Poisson model was used to find the link between environmental indicators and total cases ( $\mathrm{Li}$ et al. 2019).

It is a widely used procedure based on classical assumptions. The Poisson distribution was assumed for the dependent variable, having values like $0,1,2,3, \ldots n$. It explained the expected value $y_{i}$ by the explanatory variables $x_{i}$ (Cupal, Deev and Linnertova 2015; Raza et al. 2020) as:

$E\left\{y_{i} \mid x_{i}\right\}=\exp \left\{x_{i}^{T} \beta\right\}$.

The Poisson distribution was assumed for the count variable $y_{i}$ for given $x_{i}$ in the count data models (Raza et al. 2020).

$P\left\{y_{i}=y \mid x_{i}\right\}=\exp \left\{-\lambda_{i}\right\} \lambda_{i}^{y} / y !, \quad y=0,1,2,3, \ldots$

where $y$ ! is $y$ factorial. A suitable functional form for $\lambda_{i}$ gives expressions for the probabilities, used to build the log-likelihood function for the model, called a Poisson regression model (Raza et al. 2020). The generalized Poisson regression was better for over-dispersion $\left(\operatorname{Var}\left(y_{i}\right)>E\left(y_{i}\right)\right)$ and under-dispersion $\operatorname{Var}\left(y_{i}\right)<E\left(y_{i}\right)$. According to this, the probability density function of $y_{i}$ (Famoye 1993; Maxwell et al. 2018) was expressed as:

$f_{i}\left(y_{i}, \mu_{i}, \alpha\right)=\left(\frac{\mu_{i}}{1+\alpha \mu_{i}}\right) \frac{\left(1+\alpha y_{i}\right)^{y_{i}-1}}{y_{i} !} \exp \left[\frac{\mu_{i}\left(1+\alpha y_{i}\right)}{1+\alpha \mu_{i}}\right]$

$y_{i}=0,1,2, \ldots$ and $\mu_{i}=\mu_{i}\left(x_{i}\right)=\exp \left(x_{i} \beta\right)$

where $x_{i}$ and $\beta$ were $(k-1)$ dimensional vector of covariates and regression parameters, respectively. The mean and variance were expressed as (Raza et al. 2020):

Mean : $E\left(Y_{i} \mid x+i\right)=\mu_{i}$

Variance : $V\left(Y_{i} \mid x_{i}\right)=\mu_{i}\left(1+\alpha \mu_{i}\right)^{2}$. 


\section{Results and discussion}

\section{Descriptive analysis of COVID-19 and environmental indicators}

Table 1 shows the descriptive statistic of environmental indicators and COVID-19 cases at the national and provincial levels in Pakistan. The average wind speed was $3.285 \mathrm{~km} / \mathrm{h}$ in Pakistan. At the provincial level, the wind speed was more in Sindh $(4.499 \mathrm{~km} / \mathrm{h})$ followed by KPK $(3.230 \mathrm{~km} / \mathrm{h})$, Punjab $(3.062 \mathrm{~km} / \mathrm{h})$, and ICT $(2.350 \mathrm{~km} / \mathrm{h})$. The air pollution, amount of particulate matter (PM2.5) in the atmosphere, which was 95.435 in Pakistan. However, the PM2.5 was more in Punjab (116.895) followed by KPK (107.529), ICT (80.574), and Sindh (76.742). The average daily COVID-19 cases were 1507-957 in Pakistan, 477.756 per day in the Punjab, 661.206 per day in the Sindh, 182.182 per day in the KPK, and 80.321 in the ICT.

Figures 2, 3 and 4 show the trend of environmental indicators (wind speed and PM2.5) and COVID-19 in Pakistan from March 10, 2020, to October 04, 2020. Figure 2 shows that COVID-19 infections were continuously increased in Pakistan. On average, the COVID-19 cases were 1507.957 per day, showing a maximum value of 6825 cases on June 13, 2020. After that, the curve showed a decrease in COVID-19 cases. However, the recent situation was not satisfactory in Pakistan due to the confirmation of 600-700 COVID-19 cases per day.
Figure 3 shows that the wind speed increased between March 10, 2020, and July 21, 2020. After that, there was some reduction in wind speed. However, wind speed showed fluctuations in Pakistan from March 10, 2020, to October 04, 2020. During this period, the average wind speed was $3.285 \mathrm{~km} / \mathrm{h}$, showing a minimum $(1.85 \mathrm{~km} / \mathrm{h})$ and maximum $(5.225 \mathrm{~km} / \mathrm{h})$. Figure 4 shows the trend of air pollution in Pakistan, which was measured using the amount of PM2.5. On average, the mean of PM2.5 was 95.135 in Pakistan. The amount of PM2.5 showed fluctuation in Pakistan at both national and provincial levels. However, it was comparatively higher at the start of the COVID-19 in Pakistan. It was lowest on August 28, 2020. After that, the trend of PM2.5 was increasing in Pakistan.

\section{Correlation analysis}

The link between environmental variables and COVID19 was assessed by using Spearman's rank and Kendall's rank correlation tests. The correlation analysis explored the association of wind speed and PM2.5 with COVID-19 cases (Table 2) and the COVID-19 infection rate (Table 3). In general, the results of both tests showed a similar conclusion. The results showed that wind speed has a positive and significant correlation coefficient in Pakistan and its provinces (Punjab, Sindh, and KPK). It explains the rise in COVID-19 due to the rise in wind speed. Literature showed a positive correlation between wind speed and COVID-19 in Beijing, China (Yuan et al. 2006), and India (Gupta et al. 2020).
Table 1 Descriptive analysis of variables

\begin{tabular}{lrrrr}
\hline Indicators & \multicolumn{1}{c}{ Mean } & Minimum & Maximum & Standard deviation \\
\hline Pakistan & & & & \\
Wind speed (km/h) & 3.285 & 1.850 & 5.225 & 0.698 \\
Air pollution (PM2.5) & 95.435 & 19.108 & 51.357 & 150.750 \\
COVID-19 cases (No./day) & 1507.957 & 1.000 & 6825.000 & 1594.550 \\
Punjab & & & & \\
Wind speed (km/h) & 3.062 & 1.200 & 6.600 & 1.215 \\
Air pollution (PM2.5) & 116.895 & 46.000 & 187.000 & 36.492 \\
COVID-19 cases (No./day) & 477.756 & 0.000 & 2705.000 & 604.775 \\
Sindh & & & & \\
Wind speed (km/h) & 4.499 & 2.000 & 7.900 & 1.213 \\
Air pollution (PM2.5) & 76.742 & 42.000 & 165.000 & 19.439 \\
COVID-19 cases (No./day) & 661.206 & 0.000 & 3038.000 & 689.885 \\
KPK & & & & \\
Wind speed (km/h) & 3.230 & 2.000 & 6.100 & 1.121 \\
Air pollution (PM2.5) & 107.529 & 38.000 & 184.000 & 33.225 \\
COVID-19 cases (No./day) & 182.182 & 0.000 & 1035.000 & 188.233 \\
ICT & & & & \\
Wind speed (km/h) & 2.350 & 0.500 & 5.100 & 0.784 \\
Air pollution (PM2.5) & 80.574 & 21.000 & 147.000 & 20.536 \\
COVID-19 cases (No./day) & 80.321 & 0.000 & 771.000 & 126.394 \\
\hline
\end{tabular}


Fig. 2 Daily COVID-19 statistics in Pakistan
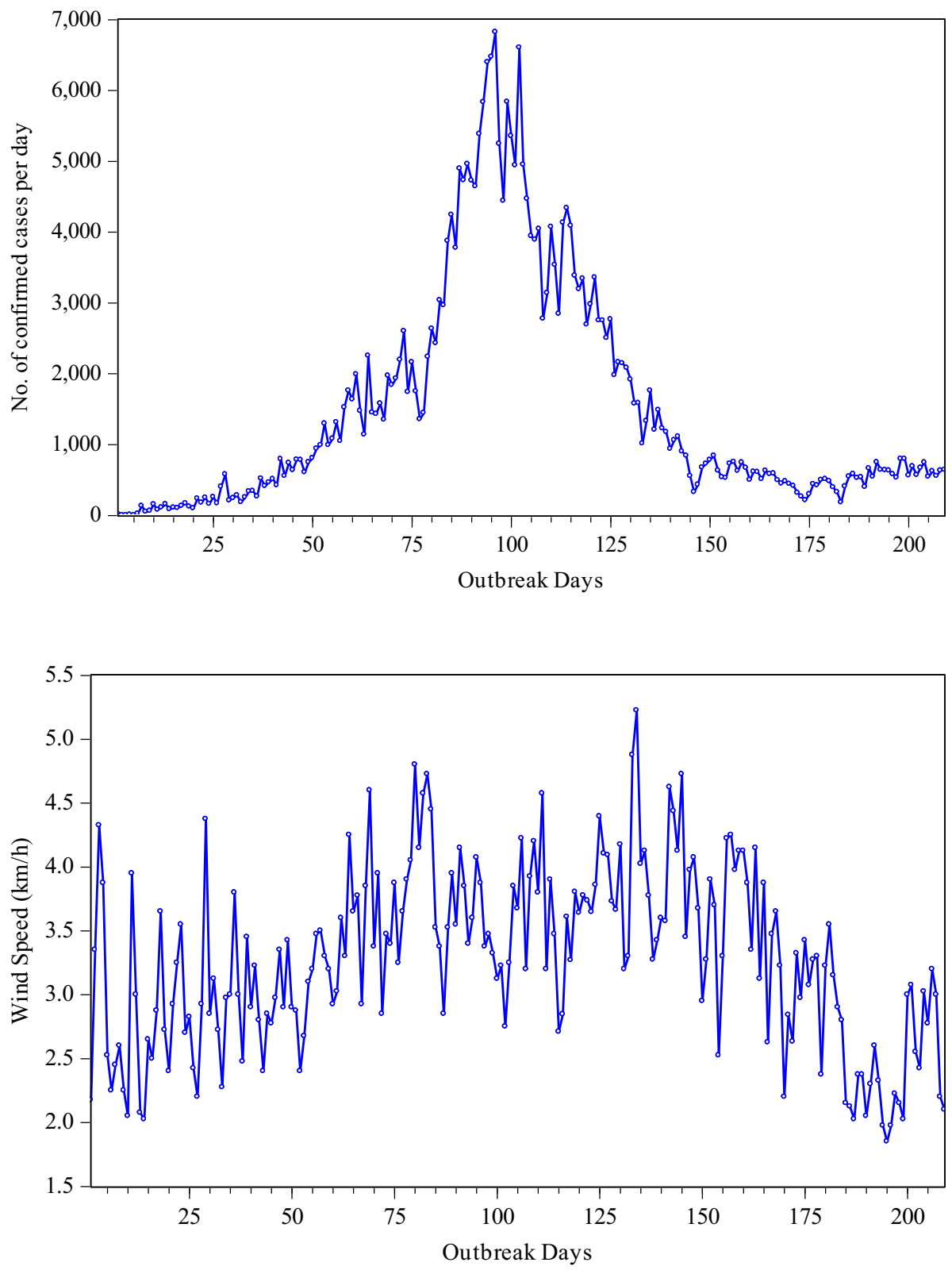

Fig. 3 The trend of wind Speed in Pakistan
However, the correlation between COVID-19 and wind speed was insignificant in the case of ICT. Contrary to these results, the negative correlation for COVID-19 and wind speed was reported in Indonesia (Rendana 2020) and Turkey (Sahin 2020). It is because the dynamics of the COVID-19 outbreaks were found highly variable in different countries or regions (Dong et al. 2020). A positive correlation was found for PM2.5 and COVID-19 in Pakistan, Punjab province, and ICT. It shows that the rise in PM2.5 concentration was also responsible for the COVID-19 in Pakistan, Punjab province, and ICT. However, a negative and significant correlation exists in the Sindh province. The wind speed was positively and significantly correlated with the COVID-19 infection rate in Pakistan and its provinces (Punjab, Sindh, and KPK). However, the correlation between PM2.5 and the COVID-19 infection rate was only significant in Sindh province (negative), KPK province (positive), and the ICT (positive). However, Zoran et al. (2020) showed a positive link between pollutants and COVID-19 in Italy. Along with these environmental indicators, people's endurance, health facilities, social distancing (Bashir et al. 2020), population density, and medical facilities (Wang et al. 2020) were also possible factors to control the COVID-19 transmission.

\section{Dose-response analysis}

The GAM was used to construct the dose-response curve for wind speed and COVID-19 (Fig. 5). In Punjab, there 
Fig. 4 The trend of air pollution (PM2.5) in Pakistan

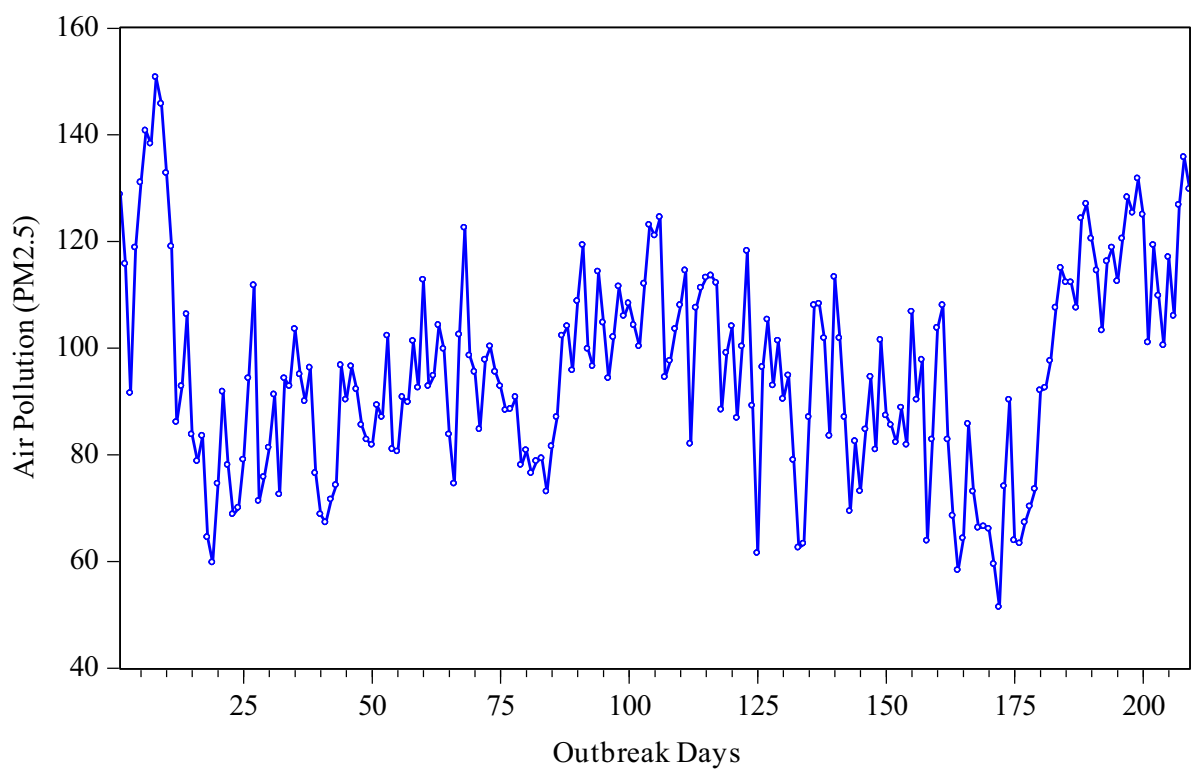

Table 2 Correlation coefficients between environmental variables and COVID-19

\begin{tabular}{lccccc}
\hline Environmental indicators & Punjab & Sindh & KPK & ICT & Pakistan \\
\hline \multicolumn{2}{l}{ Spearman's rank correlation coefficient (COVID-19 cases/day) } & & & \\
Wind speed (km/h) & $0.425^{*}$ & $0.398^{*}$ & $0.390^{*}$ & 0.037 & $0.450^{*}$ \\
Air pollution (PM2.5) & $0.134^{* * *}$ & $-0.311^{*}$ & -0.051 & $0.257^{*}$ & $0.145^{* *}$ \\
Kendall's rank correlation coefficient (COVID-19 cases/day) & & & \\
Wind speed (km/h) & $0.288^{*}$ & $0.266^{*}$ & $0.252^{*}$ & 0.025 & $0.300^{*}$ \\
Air pollution (PM2.5) & $0.096^{* *}$ & $-0.214^{*}$ & -0.023 & $0.164^{*}$ & $0.105^{* *}$ \\
Spearman's rank correlation coefficient (COVID-19 infection rate) & & & \\
Wind speed (km/h) & $0.231^{*}$ & $0.309^{*}$ & $0.381^{*}$ & 0.052 & $0.387^{*}$ \\
Air pollution (PM2.5) & -0.097 & $-0.317^{*}$ & $0.204^{*}$ & $0.229^{*}$ & -0.012 \\
Kendall's rank correlation coefficient $($ COVID-19 infection rate) & & & \\
Wind speed (km/h) & $0.151^{*}$ & $0.214^{*}$ & $0.247^{*}$ & 0.036 & $0.276^{*}$ \\
Air pollution (PM2.5) & -0.057 & $-0.225^{*}$ & $0.145^{*}$ & $0.154^{*}$ & 0.005 \\
\hline
\end{tabular}

*Significant at $1 \%, * *$ Significant at $5 \%, * *$ Significant at $10 \%$ was an inverted U-shaped curve between wind speed and COVID-19, which depicts that COVID-19 were initially increased due to an increase in wind speed, but the COVID19 cases showed reduction when wind speed was more than $4 \mathrm{~km} / \mathrm{h}$. Initially, the dose-response curve showed a direct link between wind speed and COVID-19 in Pakistan, Sindh, KPK, and ICT. After that, it becomes flattered or downward sloped in Sindh, KPK, and ICT. According to Zhang et al. (2020), the correlation between wind speed and COVID-19 was positive, negative, and insignificant in the literature.

Figure 6 shows the dose-response curve for PM2.5 and COVID-19. It showed an inverted U-shaped link between PM2.5 and COVID-19 cases per day in Pakistan, Punjab, and KPK. It explains that the COVID-19 initially increased due to a rise in PM2.5, but COVID-19 cases reduced when the amount of PM2.5 was more than the threshold level. The higher concentration of PM2.5 was also responsible to wear face masks and restricted mobility. The dose-response curve for PM2.5 and COVID-19 was positively sloped in the ICT, which means that the COVID-19 increased due to air pollution. On the other hand, the dose-response curve showed a negative link between PM2.5 and COVID-19 cases in Sindh province, showing a fall in COVID-19 due to a higher concentration of PM2.5 in the atmosphere.

\section{Generalized Poisson regression analysis}

Table 3 reveals the empirical results of generalized Poisson regression to assess the impact of wind speed and air pollution (PM2.5) on COVID-19 at the national and provincial levels in Pakistan. Yuan et al. (2006) also used a regression procedure to find the influence of wind speed, temperature, 
Table 3 Results of generalized Poisson regression

\begin{tabular}{|c|c|c|c|c|}
\hline $\begin{array}{l}\text { Environmental vari- } \\
\text { ables }\end{array}$ & Coefficient & Standard error & $z$-stat & Prob \\
\hline \multicolumn{5}{|l|}{ Pakistan } \\
\hline Constant & $1.346^{*}$ & 0.232 & 5.805 & 0.000 \\
\hline Days & $0.001 * *$ & 0.001 & 2.160 & 0.031 \\
\hline Wind speed $(\mathrm{km} / \mathrm{h})$ & $0.113^{*}$ & 0.040 & 2.796 & 0.005 \\
\hline PM2.5 & 0.001 & 0.002 & 0.500 & 0.617 \\
\hline \multicolumn{5}{|l|}{ Punjab } \\
\hline Constant & $1.235^{*}$ & 0.153 & 8.023 & 0.000 \\
\hline Days & 0.001 & 0.001 & 1.250 & 0.211 \\
\hline Wind speed $(\mathrm{km} / \mathrm{h})$ & $0.074^{*}$ & 0.025 & 3.021 & 0.003 \\
\hline PM2.5 & 0.001 & 0.001 & 1.367 & 0.172 \\
\hline \multicolumn{5}{|l|}{ Sindh } \\
\hline Constant & $1.836^{*}$ & 0.226 & 8.120 & 0.000 \\
\hline Days & $0.001 * *$ & 0.001 & 2.418 & 0.016 \\
\hline Wind speed $(\mathrm{km} / \mathrm{h})$ & $0.042 * * *$ & 0.025 & 1.668 & 0.095 \\
\hline PM2.5 & $-0.005^{*}$ & 0.002 & -2.872 & 0.004 \\
\hline \multicolumn{5}{|l|}{$K P K$} \\
\hline Constant & $1.259^{*}$ & 0.165 & 7.633 & 0.000 \\
\hline Days & $0.001 * *$ & 0.001 & 2.066 & 0.039 \\
\hline Wind speed $(\mathrm{km} / \mathrm{h})$ & $0.082 *$ & 0.029 & 2.789 & 0.005 \\
\hline PM2.5 & -0.001 & 0.001 & -1.290 & 0.197 \\
\hline \multicolumn{5}{|l|}{$I C T$} \\
\hline Constant & 0.739 & 0.785 & 0.942 & 0.346 \\
\hline Days & 0.003 & 0.003 & 1.038 & 0.299 \\
\hline Wind speed $(\mathrm{km} / \mathrm{h})$ & 0.033 & 0.031 & 1.065 & 0.287 \\
\hline PM2.5 & 0.004 & 0.005 & 0.799 & 0.424 \\
\hline
\end{tabular}

*Significant at $1 \%, * *$ Significant at $5 \%, * * *$ Significant at $10 \%$

and humidity on the SARS outbreak. Chen et al. (2020) reported that environmental indicators (wind speed and air quality) can affect the transmission of infectious diseases. According to Zhang et al. (2020), the correlation between wind speed and COVID-19 was positive, negative, and insignificant in the literature. The virus was found in the air for many hours, which implies that the transmission of the virus was influenced by wind speed (Rendana 2020). By holding the airborne factor of coronaviruses, the wind speed was accountable for the spread of the virus, by accelerating the traveling from one place to another place. Therefore, the use of face masks was suggested to slow the virus spread in different countries such as Czech Republic, Hong Kong, Slovakia, Taiwan, Thailand, and Vietnam (Sarkodie and Owusu 2020). The increase in the expected log count of COVID-19 was 0.113 times for a $1 \mathrm{~km} / \mathrm{h}$ rise in the wind speed in Pakistan. It means that the wind speed was not favorable to control COVID-19. The same conclusion was reported by Yuan et al. (2006) in Beijing, China. Yuan et al. (2006) reported that the rise in COVID-19 cases was 2.28 units for 1 unit increase in the wind speed in Beijing, China.
Moreover, Bolano-Ortiz et al. (2020) also revealed a positive association of wind speed with COVID-19 infection and mortality in the Latin American and Caribbean countries. The regression analysis of provinces and ICT revealed that the rise in expected log count of COVID-19 was 0.074 times in Punjab, 0.042 times in Sindh, and 0.082 times in KPK for a $1 \mathrm{~km} / \mathrm{h}$ increase in the wind speed. However, there was no significant association between wind speed and COVID119 in ICT. However, the impact of PM2.5 on the COVID19 was not significant in Pakistan. It means that the rise in PM2.5 was not responsible for the COVID-19 in Pakistan. The impact of PM2.5 on the COVID-19 transmission was also insignificant in Punjab, KPK, and ICT. However, the fall in the expected log count of COVID-19 cases was 0.005 times in Sindh. Wu et al. (2020) mentioned that the PM2.5 in the atmosphere was linked with the rise in the COVID19 deaths in the United States. The PM2.5 showed adverse health impact through inhalation because PM2.5 can be deposited in the lungs, which further increased the probability of cardio-respiratory diseases (Zoran et al. 2020).

\section{Conclusion}

The world economy and public health faced huge problems due to the COVID-19 outbreak. This study investigated the impact of wind speed and air pollution (PM2.5) on COVID-19 in Pakistan from March 10, 2020, to October 04, 2020. Wind speed has a positive and significant correlation coefficient in Pakistan and its provinces (Punjab, Sindh, and KPK). The dose-response curve for wind speed and COVID-19 was like an inverted U-shaped curve, which means that COVID-19 initially increased due to wind speed, but the COVID-19 cases showed reduction when wind speed was more than $4 \mathrm{~km} / \mathrm{h}$. The dose-response curve initially reflected a positive link between wind speed and COVID19 infection in Pakistan, Sindh, KPK, and ICT. After that, it becomes flattered or downward sloped in Sindh, KPK, and ICT. The expected log count of COVID-19 infection was increased by 0.113 times (Pakistan), 0.074 times (Punjab), 0.042 times (Sindh), and 0.082 times (KPK) for a $1 \mathrm{~km} / \mathrm{h}$ increase in the wind speed. The correlation between PM2.5 and COVID-19 was also positive in Pakistan, Punjab, and ICT. However, a negative and significant correlation exists in the Sindh. The dose-response curve for PM2.5 and COVID-19 was inverted U-shaped in Pakistan, Punjab province, and KPK province. It reflects the initial increase in the COVID-19 for an increase in PM2.5, but COVID-19 cases reduced when the amount of PM2.5 was more than the threshold level. The higher concentration of PM2.5 was also responsible to wear face masks and restricted mobility. The dose-response curve for PM2.5 and COVID-19 was positively sloped in ICT, which depicts the rise in COVID-19 

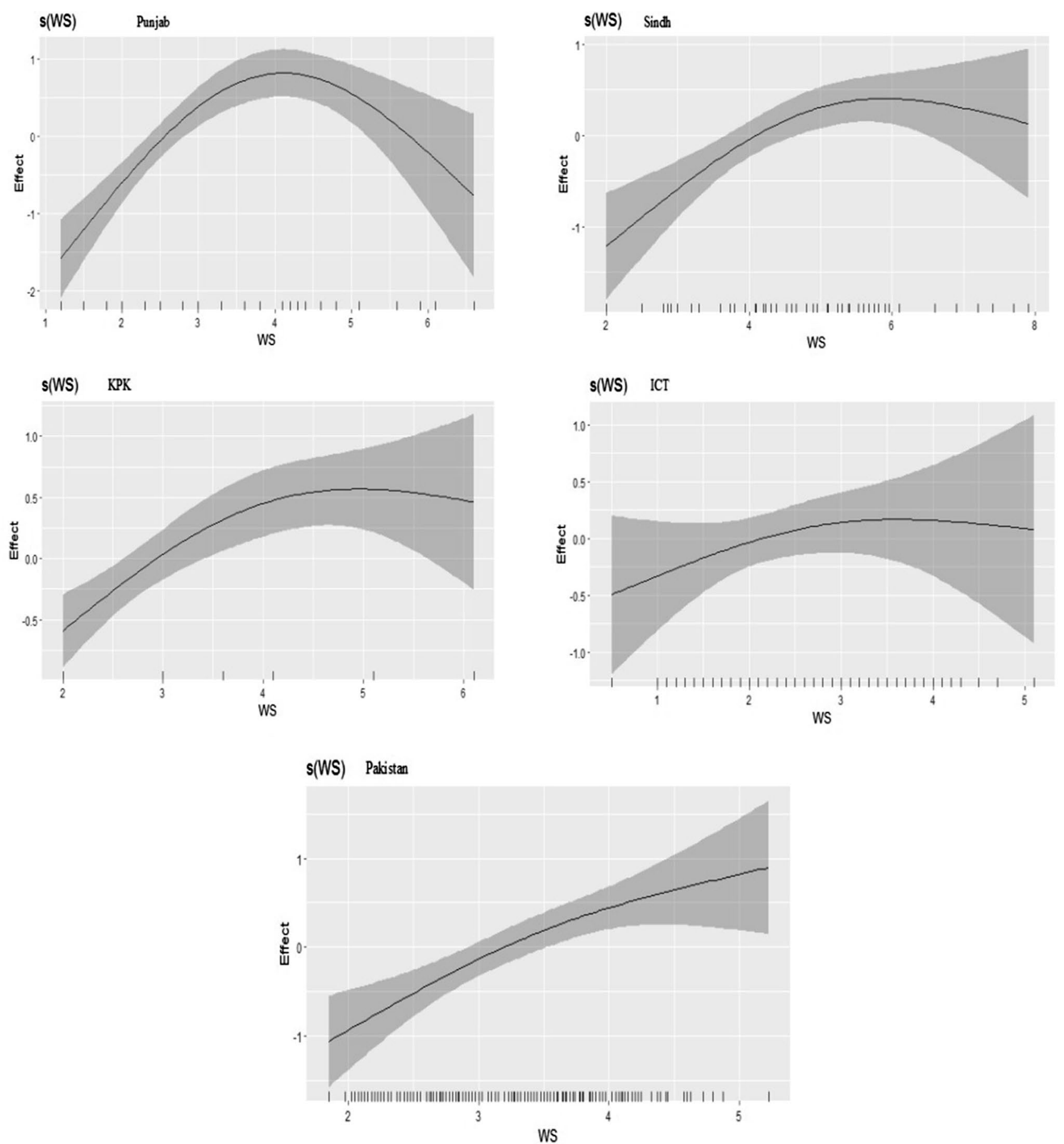

Fig. 5 The dose-response curves for wind speed and COVID-19

infection due to higher air pollution. On the other hand, the dose-response curve showed a negative link between PM2.5 and COVID-19 in Sindh province. However, the regression impact of PM2.5 on the COVID-19 was insignificant in Pakistan. The regression impact of PM2.5 on the COVID19 transmission was also insignificant in Punjab, KPK, and ICT. However, a fall in the expected log count of COVID-19 was 0.005 times in Sindh for a 1 unit rise in PM2.5. This research has some limitations such as (a) the COVID-19 can be affected by some other indicators like population density, mobility, age of the person, people endurance, and biological properties of virus (b) it is also important to find the impact of some other air pollutants $\left(\mathrm{CO}, \mathrm{SO}_{2}, \mathrm{NO}_{2}, \mathrm{PM} 10\right)$ on the COVID-19 transmission. 

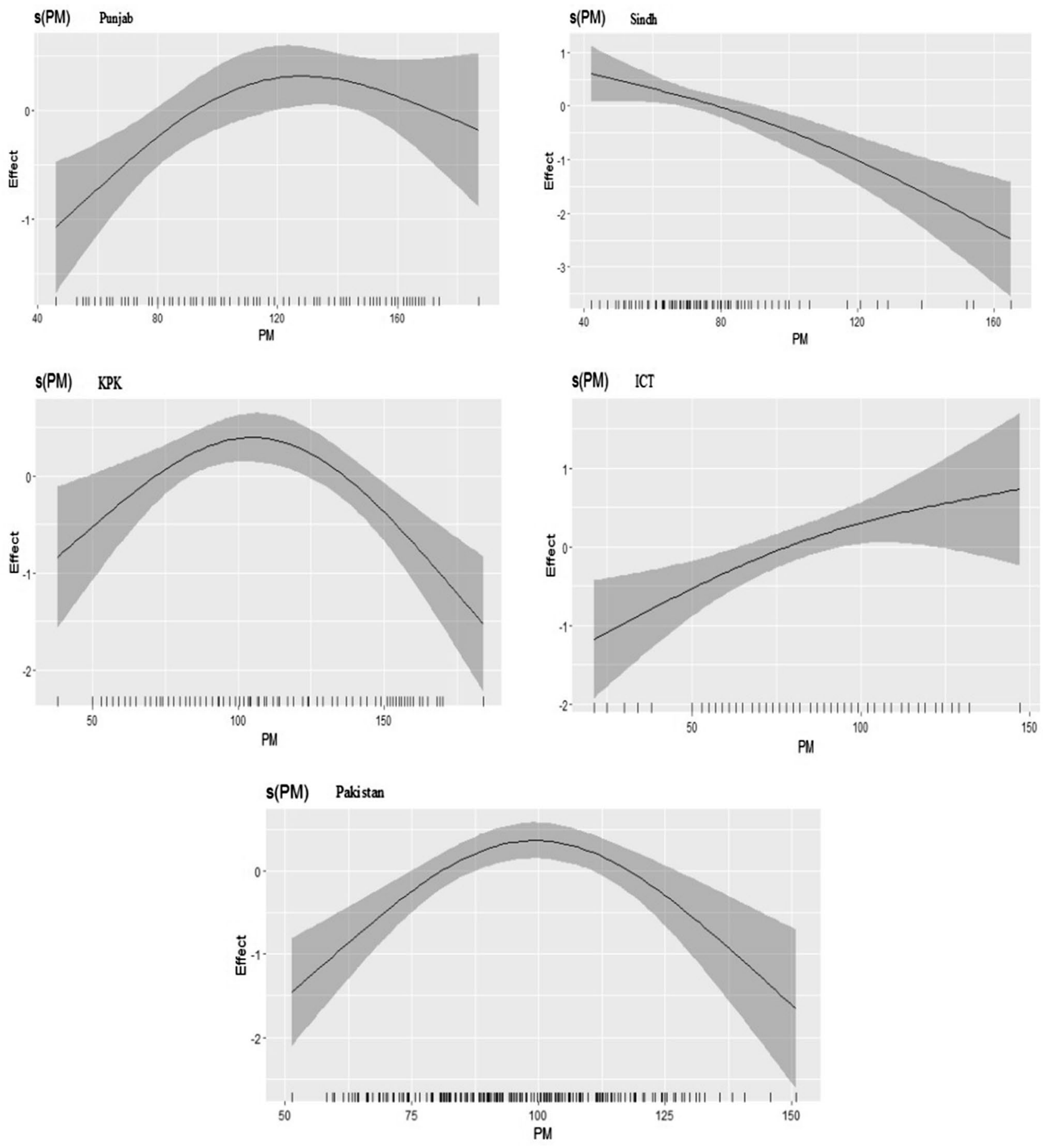

Fig. 6 The dose-response curves for air pollution (PM2.5) and COVID-19

Acknowledgements The authors of the publication would like to express their gratitude to the Government of Pakistan for the provision of day-wise COVID-19 data.

Author contributions QA and AR contributed to conceptualization, methodology, and software; SS contributed to data curation and writing-original draft preparation; and MTIK contributed to writingreviewing and editing.
Funding This research has no funding from any organization.

Availability of data and material Data will be available on request. 


\section{Compliance with ethical standards}

Conflict of interest The authors declare that they have no conflict of interest.

Ethical approval This article does not contain any studies with human participants or animals performed by any of the authors.

\section{References}

Air Quality Open Data Platform (2020) https://aqicn.org/data-platf orm/covid19/verify/ee3d5b76-ce56-4b24-9491-a0a183b39d68. Accessed 31 May 2020

Andree BPJ (2020) Incidence of COVID-19 and connections with air pollution exposure: evidence from the Netherlands. Policy Research Working Paper 9221, World Bank Group, Strategy, Analytics, Financing Solutions and Knowledge Unit

Bashir MF, Ma B, Komal B, Bashir MA, Tan D, Bashir M (2020) Correlation between climate indicators and COVID-19 pandemic in New York, USA. Sci Total Environ 728:138835. https://doi. org/10.1016/j.scitotenv.2020.138835

Bolano-Ortiz TR, Camargo-Caicedo Y, Puliafto SE, Ruggeri MF, Bolano-Diaz S, Pascual-Flores R, Saturno J, Ibarra-Espinosa S, Mayol-Bracero OL, Torres-Delgado E, Cereceda-Balic F (2020) Spread of SARS-CoV-2 through Latin America and the Caribbean region: a look from its economic conditions, climate and air pollution indicators. Environ Res 191:109938. https://doi. org/10.1016/j.envres.2020.109938

Brouwer AF, Weir MH, Eisenberg MC, Meza R, Eisenberg JNS (2017) Dose-response relationships for environmentally mediated infectious disease transmission models. PLoS Comput Biol 13(4):e1005481. https://doi.org/10.1371/journal.pcbi.1005481

Cai Q, Lu J, Xu Q, Guo Q, Xu D, Sun Q, Yang H, Zhao G, Jiang Q (2007) Influence of meteorological factors and air pollution on the outbreak of severe acute respiratory syndrome. Public Health 121:258-265

Chan JFW, Yuan S, Kok KH, To KKW, Chu H, Yang J, Xing F, Liu J, Yip CCY, Poon RWS, Tsoi HW, Lo SKF, Chan KH, Poon VKM, Chan WM, Ip JD, Cai JP, Cheng VCC, Chen H, Hui CKM, Yuen KY (2020) A familial cluster of pneumonia associated with the 2019 novel coronavirus indicating person to-person transmission: a study of a family cluster. Lancet 395:514-523. https://doi. org/10.1016/S0140-6736(20)30154-9

Chen B, Liang H, Yuan X, Hu Y, Xu M, Zhao Y, Zhang B, Tian F, Zhu X (2020) Roles of meteorological conditions in COVID19 transmission on a worldwide scale. medRxiv. https://doi. org/10.1101/2020.03.16.20037168

Consul PC, Famoye F (1992) Generalized poisson regression model. Comm Stat-Theory Methods 21:89-109. https://doi. org/10.1080/03610929208830766

Cupal M, Deev O, Linnertova D (2015) The Poisson regression analysis for occurrence of floods. Procedia Econ Finance 23:14991502. https://doi.org/10.1016/S2212-5671(15)00465-7

Dong E, Du H, Gardner L (2020) An interactive web-based dashboard to track COVID-19 in real time. Lancet Infect Dis. https://doi. org/10.1016/S1473-3099(20)30120-1

Famoye F (1993) Restricted generalized Poisson regression model. Comm Stat-Theory Methods 22:1335-1354

Famoye F (2015) A multivariate generalized Poisson regression model. Comm Stat-Theory Methods 44:497-511. https://doi. org/10.1080/03610926.2012.743565

Goswami K, Bharali S, Hazarika J (2020) 'Projections for COVID19 pandemic in India and effect of temperature and humidity.
Diabetes Metab Syndr Clin Res Rev 14:801-805. https://doi. org/10.1016/j.dsx.2020.05.045

Government of Pakistan (GOP) (2020) http://covid.gov.pk/stats/pakis $\tan$. Accessed 18 Oct 2020

Gupta A, Banerjee S, Das S (2020) Signifcance of geographical factors to the COVID-19 outbreak in India. Model Earth Syst Environ 6:2645-2653. https://doi.org/10.1007/s40808-020-00838-2

Hamadeh N, Karouni A, Daya B, Chauvet P (2017) Using correlative data analysis to develop weather index that estimates the risk of forest fires in Lebanon \& Mediterranean: assessment versus prevalent meteorological indices. Case Stud Fire Saf 7:8-22. https://doi.org/10.1016/j.csfs.2016.12.001

Huang C, Wang Y, Li X, Ren L, Zhao J, Hu Y, Zhang L, Fan G, Xu J, Gu X, Cheng Z, Yu T, Xia J, Wei Y, Wu W, Xie X, Yin W, Li H, Liu M, Xiao Y, Gao H, Guo L, Xie J, Wang G, Jiang R, Gao Z, Jin Q, Wang J, Cao B (2020) Clinical features of patients infected with 2019 novel coronavirus in Wuhan, China. Lancet 395:497-506. https://doi.org/10.1016/S0140-6736(20)30183-5

Hussain M, Liu G, Yousaf B, Ahmed R, Uzma F, Ali MU, Ullah H, Butt AR (2018) Regional and sectoral assessment on climatechange in Pakistan: social norms and indigenous perceptions on climate-change adaptation and mitigation in relation to global context. J Clean Prod 200:791-808. https://doi.org/10.1016/j. jclepro.2018.07.272

IQAir (2019) World Air Quality Report 2019. https://www.iqair.com/ world-most-polluted-cities/world-air-quality-report-2019-en.pdf

Khan S, Khan M, Maqsood K, Hussain T, Zeeshan M (2020) Is Pakistan prepared for the COVID-19 epidemic? A questionnairebased survey. J Med Virol. https://doi.org/10.1002/jmv.25814

Kocsis T, Anda A (2018) Parametric or non-parametric: analysis of rainfall time series at a Hungarian meteorological station. Q J Hung Meteorol Serv 122(2):203-216. https://doi.org/10.28974 /idojaras.2018.2.6

Li X, Wang N, Ding G, Li X, Xue X (2019) The relationship between meteorological factors and the risk of bacillary dysentery in Hunan Province, China. Weather 74(4):148-153

Maxwell O, Mayowa BA, Chinedu IU, Peace AE (2018) Modelling count data; a generalized linear model framework. Am J Math Stat 8(6):179-183. https://doi.org/10.5923/j.ajms.20180806.03

Raza A, Khan MTI, Ali Q, Hussain T, Narjis S (2020) Association between meteorological indicators and COVID-19 pandemic in Pakistan. Environ Sci Pollut Res. https://doi.org/10.1007/s1135 6-020-11203-2

Rendana M (2020) Impact of the wind conditions on COVID-19 pandemic: a new insight for direction of the spread of the virus. Urban Climate 34:100680. https://doi.org/10.1016/j.uclim .2020 .100680

Rosario DKA, Mutz YS, Bernardes PC, Conte-Junior CA (2020) Relationship between COVID-19 and weather: case study in a tropical country. Int J Hyg Environ Health 229:113587. https://doi. org/10.1016/j.ijheh.2020.113587

Şahin M (2020) Impact of weather on COVID-19 pandemic in Turkey. Sci Total Environ 728:138810. https://doi.org/10.1016/j.scito tenv.2020.138810

Sarkodie SA, Owusu PA (2020) Impact of meteorological factors on COVID-19 pandemic: evidence from top 20 countries with confrmed cases. Environ Res 191:110101. https://doi.org/10.1016/j. envres.2020.110101

Shereen MA, Khan S, Kazmi A, Bashir N, Siddique R (2020) COVID19 infection: origin, transmission, and characteristics of human coronaviruses. J Adv Res 24:91-98. https://doi.org/10.1016/j. jare.2020.03.005

Siciliano B, Dantas G, Silva CMD, Arbilla G (2020) Increased ozone levels during the COVID-19 lockdown: analysis for the city of Rio de Janeiro, Brazil. Sci Total Environ 737:139765. https://doi. org/10.1016/j.scitotenv.2020.139765 
Stott P (2016) CLIMATE CHANGE. How climate change affects extreme weather events. Science 352(6293):1517-1518. https:// doi.org/10.1126/science.aaf7271

Syed F, Sibgatullah S (2020) Estimation of the final size of the COVID-19 epidemic in Pakistan. medRxiv. https://doi. org/10.1101/2020.04.01.20050369

Toppi LSD, Toppi LSD, Bellini E (2020) Novel coronavirus: how atmospheric particulate affects our environment and health. Challenges 11:6. https://doi.org/10.3390/challe11010006

Wang M, Jiang A, Gong L, Luo L, Guo W, Li C, Zheng J, Li C, Yang B, Zeng J, Chen Y, Zheng K, Li H (2020) Temperature significant change COVID-19 transmission in 429 cities. medRxiv. https:// doi.org/10.1101/2020.02.22.20025791

World Health Organization (WHO) (2020) World Heath Organization. https://www.who.int/emergencies/diseases/novel-coronaviru s-2019/situation-reports/. Accessed 18 Oct 2020

Wu X, Nethery RC, Sabath BM, Braun D, Dominici F (2020) Exposure to air pollution and COVID-19 mortality in the United States: a nationwide cross-sectional study. J Chem Inf Model. https://doi. org/10.1101/2020.04.05.20054502
Xu H, Yan C, Fu Q, Xiao K, Yu Y, Han D, Wang W, Cheng J (2020) Possible environmental effects on the spread of COVID-19 in China. Sci Total Environ 731:139211. https://doi.org/10.1016/j. scitotenv.2020.139211

Ye T, Liu W, Mu Q, Zong S, Li Y, Shi P (2020) Quantifying livestock vulnerability to snow disasters in the Tibetan Plateau: comparing different modeling techniques for prediction. Int J Disaster Risk Reduct 48:101578

Yuan J, Yun H, Lan W, Wang W, Sullivan SG, Jia S, Bittles AH (2006) A climatologic investigation of the SARS-CoV outbreak in Beijing, China. Am J Infect Control 34:234-236. https://doi. org/10.1016/j.ajic.2005.12.006

Zhang Z, Xue T, Jin X (2020) Effects of meteorological conditions and air pollution on COVID-19 transmission: evidence from 219 Chinese cities. Sci Total Environ 741:140244. https://doi. org/10.1016/j.scitotenv.2020.140244

Zoran MA, Savastru RS, Savastru DM, Tautan MN (2020) Assessing the relationship between surface levels of PM2.5 and PM10 particulate matter impact on COVID-19 in Milan, Italy. Sci Total Environ 738:139825. https://doi.org/10.1016/j.scitotenv.2020.139825 